\title{
A high-pressure x-ray photoelectron spectroscopy instrument for studies of industrially relevant catalytic reactions at pressures of several bars
}

Cite as: Rev. Sci. Instrum. 90, 103102 (2019); https://doi.org/10.1063/1.5109321

Submitted: 08 May 2019 . Accepted: 04 September 2019. Published Online: 08 October 2019

Peter Amann (D), David Degerman (D), Ming-Tao Lee, John D. Alexander, Mikhail Shipilin, Hsin-Yi Wang (D), Filippo Cavalca, Matthew Weston, Jörgen Gladh (D), Mikael Blom, Mikael Björkhage, Patrik Löfgren, Christoph Schlueter, Patrick Loemker (D), Katrin Ederer, Wolfgang Drube (D), Heshmat Noei (D), Johann Zehetner, Henrik Wentzel, John Åhlund, and Anders Nilsson

\section{COLLECTIONS}

F This paper was selected as Featured

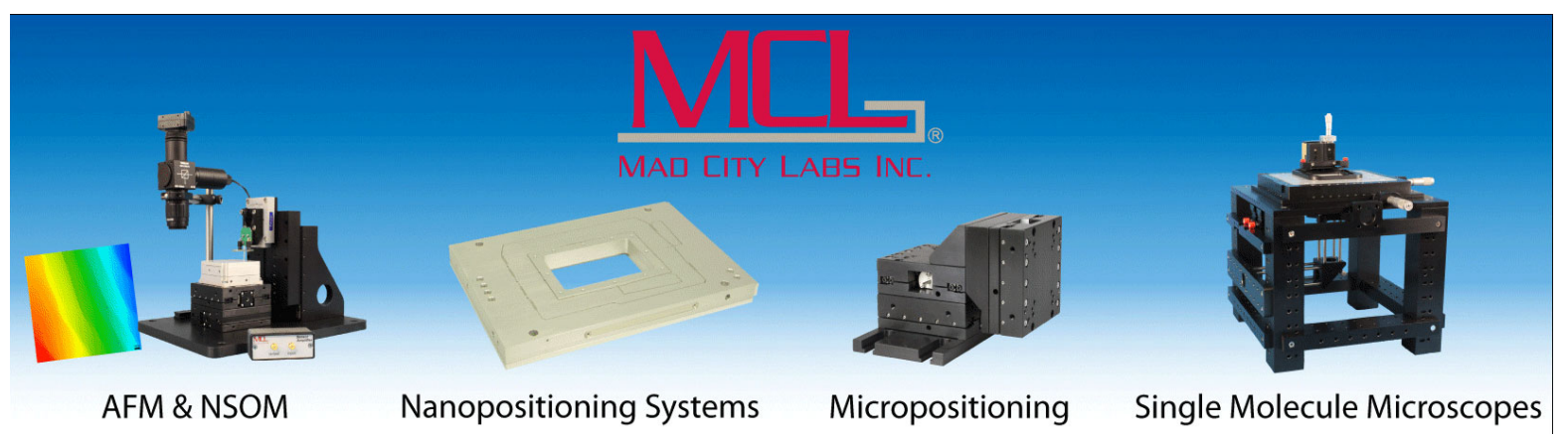




\title{
A high-pressure x-ray photoelectron spectroscopy instrument for studies of industrially relevant catalytic reactions at pressures of several bars
}

Cite as: Rev. Sci. Instrum. 90, 103102 (2019); doi: 10.1063/1.5109321

Submitted: 8 May 2019 - Accepted: 4 September 2019 •

Published Online: 8 October 2019

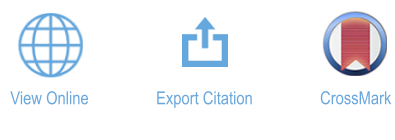

\begin{abstract}
Peter Amann, ${ }^{1, a)}$ (D) David Degerman,' (D) Ming-Tao Lee,' John D. Alexander,' Mikhail Shipilin,'
Hsin-Yi Wang, ${ }^{1}$ (D) Filippo Cavalca, ${ }^{1}$ Matthew Weston, ${ }^{\prime}$ Jörgen Gladh, ${ }^{1 D}$ Mikael Blom, ${ }^{1}$ Mikael Björkhage,

Patrik Löfgren, ${ }^{1}$ Christoph Schlueter, ${ }^{2}$ Patrick Loemker, ${ }^{2}$ (i) Katrin Ederer, ${ }^{2}$ Wolfgang Drube,

Heshmat Noei, ${ }^{3}$ (D) Johann Zehetner, ${ }^{4}$ Henrik Wentzel, ${ }^{5}$ John Åhlund, ${ }^{6}$ and Anders Nilsson'
\end{abstract}

\begin{abstract}
AFFILIATIONS
1 Department of Physics, Stockholm University, AlbaNova University Center, 10691 Stockholm, Sweden

${ }^{2}$ Photon Science, Deutsches Elektronen-Synchrotron DESY, Notkestr. 85, 22607 Hamburg, Germany

${ }^{3}$ DESY NanoLab, Deutsches Elektronen-Synchrotron DESY, 22607 Hamburg, Germany

${ }^{4}$ Research Centre for Mikrotechnology, University of Applied Sciences, Hochschulstrasse 1, 6850 Dornbirn, Austria

${ }^{5}$ Teknikvetenskap Royal Institute of Technology (KTH), Teknikringen 8D, SE-100 44 Stockholm, Sweden

${ }^{6}$ Scienta Omicron AB, P.O. Box 15120, SE-750 15 Uppsala, Sweden
\end{abstract}

a) Author to whom correspondence should be addressed: peter.amann@fysik.su.se

\begin{abstract}
We present a new high-pressure x-ray photoelectron spectroscopy system dedicated to probing catalytic reactions under realistic conditions at pressures of multiple bars. The instrument builds around the novel concept of a "virtual cell" in which a gas flow onto the sample surface creates a localized high-pressure pillow. This allows the instrument to be operated with a low pressure of a few millibar in the main chamber, while simultaneously a local pressure exceeding 1 bar can be supplied at the sample surface. Synchrotron based hard x-ray excitation is used to increase the electron mean free path in the gas region between sample and analyzer while grazing incidence $<5^{\circ}$ close to total external refection conditions enhances surface sensitivity. The aperture separating the high-pressure region from the differential pumping of the electron spectrometer consists of multiple, evenly spaced, micrometer sized holes matching the footprint of the $\mathrm{x}$-ray beam on the sample. The resulting signal is highly dependent on the sample-to-aperture distance because photoemitted electrons are subject to strong scattering in the gas phase. Therefore, high precision control of the sample-to-aperture distance is crucial. A fully integrated manipulator allows for sample movement with step sizes of $10 \mathrm{~nm}$ between 0 and $-5 \mathrm{~mm}$ with very low vibrational amplitude and also for sample heating up to $500{ }^{\circ} \mathrm{C}$ under reaction conditions. We demonstrate the performance of this novel instrument with bulk $2 p$ spectra of a copper single crystal at He pressures of up to 2.5 bars and $\mathrm{C} 1 s$ spectra measured in gas mixtures of $\mathrm{CO}+\mathrm{H}_{2}$ at pressures of up to 790 mbar. The capability to detect emitted photoelectrons at several bars opens the prospect for studies of catalytic reactions under industrially relevant operando conditions.
\end{abstract}

Published under license by AIP Publishing. https://doi.org/10.1063/1.5109321

\section{INTRODUCTION}

The chemical industry converts raw materials into thousands of different products ${ }^{1}$ and is therefore at the foundation of our economy and a major contributor to the GPD in the western world. It is estimated that nearly $90 \%$ of all chemical products rely on suitable catalysts that enhance the rate of chemical reactions. ${ }^{2}$ Central to catalysis is the formation and breaking of chemical bonds at catalytically active surfaces and interfaces. These surfaces themselves can restructure due to the interaction with the reacting gas. This results in a wealth of possible reaction pathways with numerous intermediate and final products. The enormous variety in applications for catalysis calls for a deeper understanding of how catalytic materials facilitate the reaction 
processes such that highly active and selective catalysts can be designed.

$\mathrm{X}$-ray photoelectron spectroscopy (XPS) is one of the primary tools to investigate chemical compositions of surfaces. ${ }^{3}$ The technique's inherent surface sensitivity derives from the short mean free path (MFP) of electrons inside materials of typically only a few nanometers. Consequently, over the last 5 decades, XPS has been used extensively to study interactions between molecules and surfaces. ${ }^{4,5}$ Well-controlled and systematic studies of single crystal surfaces under ultrahigh vacuum conditions (UHV) provided a wealth of information. ${ }^{6,7}$ Classically, the application of XPS to more realistic systems, such as solid-liquid and solid-gas interfaces at high pressures, is limited due to strong inelastic scattering of the photoemitted electrons. ${ }^{8,9}$ However, most important heterogeneous catalytic reactions occur at high pressures and temperatures. Furthermore, it is not clear how easily we can transfer knowledge from UHV experiments to real catalytic reactions. The challenge is to follow the chemical bond formation and breaking, and catalyst restructuring while the reaction takes place under realistic conditions, i.e., at pressure of several bars in combination with temperatures of several hundred degree Celsius.

Continuous technical improvements have extended XPS to the use of synchrotron radiation ${ }^{4,5}$ and resulted in modern instruments reaching into pressure regimes of several 10 s of mbar. ${ }^{10-15}$ These instruments often take advantage of a combination of differential pumping and an electrostatic prelens section in electron spectrometers. ${ }^{8,16-21}$ Apertures of several hundred micrometers in diameter are used to limit the gas flow from the high-pressure region to the differential pumping section of the analyzer. A pressure difference of several orders of magnitude is achieved between the region surrounding the sample and the first differential pumping stage.

The pressure distribution around the first aperture is not homogeneous and decreases in close proximity to the aperture in comparison to the chamber pressure, where the sample is located ${ }^{22,23}$ (see Sec. V C for further details). Assuming an infinitely thin wall separating the interaction region from the differential pumped sections of the electron analyzer and molecular flow conditions, the pressure profile close to the aperture follows a sigmoidal function $P(x)=0.5 P_{0}\left(1-\frac{x}{\sqrt{1+x^{2}}}\right)$, where $P_{0}$ is the pressure in the chamber and $x$ the distance along the length axis of the aperture. Analytical as well as numerical simulations resulted in a common understanding that the distance between the sample and the front cone needs to be at least 1 time the aperture diameter to have $90 \%$ of the chamber pressure and 2 times the aperture diameter to have $99 \%$ of the chamber pressure at the position of the sample surface. $^{22,24}$ Therefore, it is common practice to run the experiment with sample-to-aperture distance of 1-2 times the aperture diameter, while the sample is positioned in a chamber or an in situ cell with gas-backfilling to the millibar regime, as commonly implemented.

To date, two distinctly different sample environments have been established. In the backfill- or exchangeable chamber approach, the whole chamber is filled to the desired pressure conditions for the sample. ${ }^{25-29}$ The advantage of this approach is that other tools inside the experimental chamber like ion gun or evaporating sources can easily access the sample. The disadvantages are that (i) dependent upon the chamber volume, a large amount of gas is used to fill the chamber and (ii) the chamber walls can contribute to contamination of the experiment. Such disadvantages can be minimized by the use of exchangeable chambers between different classes of experiments.

In situ cells, consisting of small chambers placed inside the main vacuum chamber, offer the advantage of a small volume with reduced surface area where the resulting contaminations are reduced and gas consumption is low. ${ }^{26,27,29-31}$ However, the cell design is often complicated, as it needs to allow for loading and unloading of samples in short time and for X-rays to enter. In both cases, the in situ cells as well as backfill-or exchangeable chamber approach, the pressure is limited to 1 bar as vacuum chambers are not designed to handle overpressure.

More recent developments include the use of graphene and Si membranes for electrochemical and gas-phase application ${ }^{32-37}$ as well as hydrogen permeation membranes ${ }^{38}$ and also pulsed valves for the creation of dynamic pressures. ${ }^{13,39}$ In the latter approach, a highly collimated gas jet is pointed to the sample surface from several millimeter distance. Pulsing the jet allows for studying the pressure-time behavior of different systems.

Here, we describe an instrument specifically designed to perform catalytic measurements at pressures of several bars. We employ an alternative to the classical cell approach, consisting of a "virtual cell." Scattering by the gas phase is reduced by decreasing the sample-to-aperture distance to a few $10 \mathrm{~s}$ of $\mu \mathrm{m}$. To facilitate this, gas dosing is integrated into the front cone and directed directly onto the sample leading to a very localized high-pressure pocket. The virtual cell approach allows reaching local pressures of several bars while keeping the chamber pressure in a relatively low-pressure regime. The system was built for synchrotron and free electron laser measurements and is currently situated at the hard x-ray beamline P22 at DESY (Hamburg, Germany). ${ }^{40,41}$ The instrument offers flexibility toward fast transportation and adjustment to different beam heights. Here, we specifically report on extensive effort put into the development of new approaches in sample holder and sample manipulator design, front cone design, positioning systems, as well as gas handling system.

This instrument is opening a window to XPS studies in previously inaccessible pressure and temperature regimes and is expected to give fundamentally new insights into the mechanisms governing industrially relevant catalytic reactions under more realistic conditions.

\section{SYSTEM OVERVIEW}

The instrument follows a modular design with three main components: (i) an electron analyzer (Scienta-Omicron, R4000-HiPP2), (ii) a main chamber, and (iii) a high precision hexapod for alignment. An overview is shown in Fig. 1.

The analyzer has a standard configuration ${ }^{19,42}$ and is placed in a horizontal geometry to match the E-vector of photons generated by a synchrotron undulator. The lens tables are optimized for high transmission up to $\sim 9.3 \mathrm{keV}$, with little compromise for kinetic energies below $200 \mathrm{eV}$. The energy resolution is determined by the combination of 9 interchangeable slits $(0.2-4 \mathrm{~mm}$, curved and straight) and pass energies up to $200 \mathrm{eV}$. The radius of the central trajectory through the analyzer hemisphere is $200 \mathrm{~mm}$. The multichannel plate (MCP) detector captures a kinetic energy window 

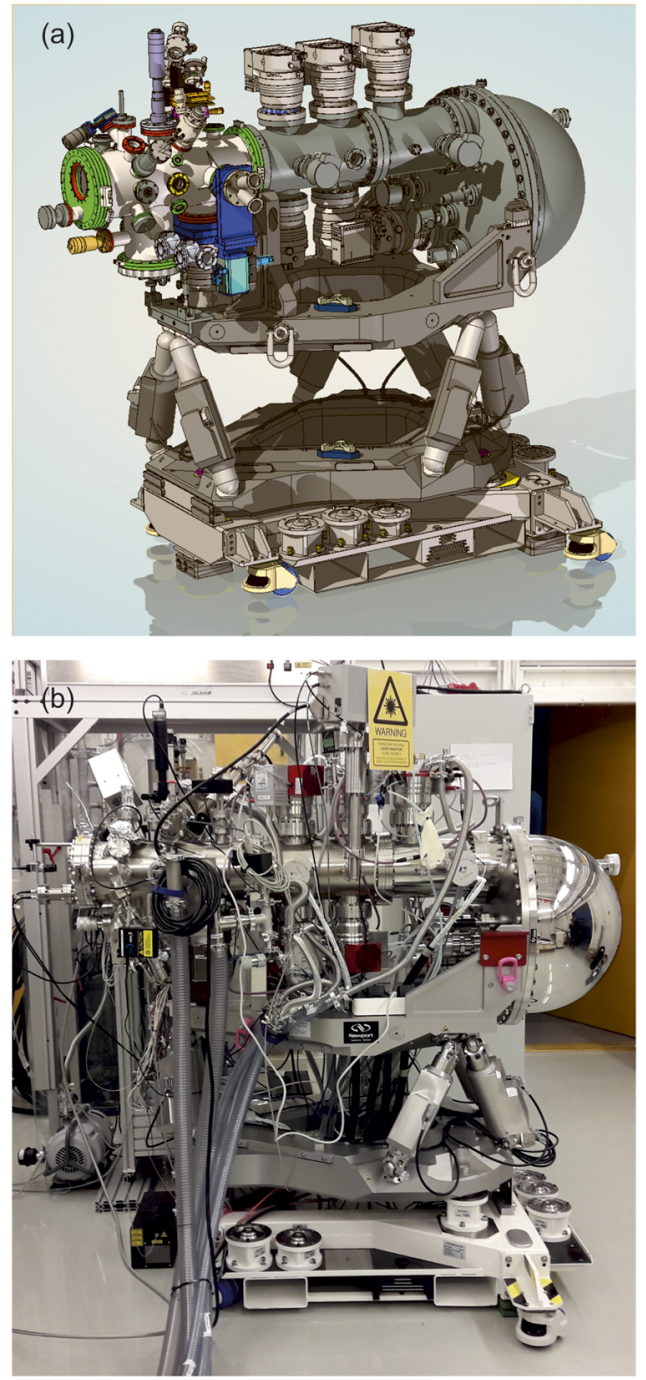

FIG. 1. (a) A 3D CAD drawing of the system and (b) a photograph of the system as installed at beamline P22 at Petralll. The setup is dedicated to run under highpressure conditions and offers the flexibility to move to various $x$-ray sources such as synchrotrons and free electron lasers.

of $\sim 8 \%$ of the pass energy and is imaged with a Basler scout CCD camera.

Attached to the electron analyzer is a compact mu-metal vacuum chamber that includes a total of 28 ports. X-rays can enter the vacuum chamber in three different ways. Two symmetrically oriented ports at $90^{\circ}$ with respect to the electron analyzer lens axis allow for incidence angles between $\pm 5^{\circ}$. The symmetric arrangement gives flexibility to position the instrument at different beamlines with orientation of $\pm 90^{\circ}$ with respect to the $\mathrm{x}$-ray beam and also provides the option for tandem operation in which the beam is passed to instruments placed farther downstream. A third port, oriented at $55^{\circ}$ with respect to the analyzer lens axis, can be used with traditional front cone designs from Scienta-Omicron. Other ports of the vacuum chamber are available for sample manipulation, $\mathrm{Ar}^{+}$ion sputtering, an electron gun (e-gun), $\mathrm{H}_{2}$ plasma cleaning, fast bakeout through UV-light sources, gas dosing through backfilling of the vacuum chamber, pumping, and provide some flexibility for other setup extensions that demand electrical or liquid feedthroughs. For increased stability, the sample manipulator is integrated into the vacuum chamber.

A sample change typically takes $2 \mathrm{~h}$ and is conducted through venting and opening a DN200 CF flange opposite of the electron analyzer. This time includes venting, opening of the vacuum chamber, exchanging the sample, closing the chamber, and pumping down to about $10^{-6} \mathrm{mbar}$. The front cone of the electron analyzer can be accessed through the same port.

The electron analyzer and vacuum chamber are mounted on a hexapod system (Newport, custom design) optimized to meet the instrument requirements. It allows for transport by crane and forklift or by pushing on castor wheels. High-precision water levels are permanently installed for prealigning of the instrument within $\pm 20 \mu \mathrm{rad}$. The hexapod legs allow for precise manipulation of the entire instrument within $\pm 25 \mathrm{~mm}$ in the horizontal (X, Y) plane and $\pm 20 \mathrm{~mm}$ in the vertical ( $\mathrm{Z}$ ) direction, as well as rotation around each individual axis of $\pm 0.5^{\circ}$ in the tip and tilt ( $\mathrm{Rx}$ and $\mathrm{Ry}$ ) direction and $\pm 5^{\circ}$ rotation in $\mathrm{Rz}$. The resolution is $0.1 \mu \mathrm{m}$ in the $\mathrm{X}$, $\mathrm{Y}$, and $\mathrm{Z}$ directions, $2 \mu \mathrm{rad}$ in rotation around $\mathrm{Rz}$, and $1 \mu \mathrm{rad}$ around $\mathrm{Rx}$ and $\mathrm{Ry}$. The overall extent of the instrument was chosen in a delicate compromise between stability and space restrictions given by the beamline layout. The sample height is adjustable between 1320 and $1600 \mathrm{~mm}$ above the floor level by use of spacers of various sizes to match the beam height of different light sources.

The overall design with a top heavy mass, however, results in the system behaving like an inverted pendulum. The heavy weight of $\sim 500 \mathrm{~kg}$ (analyzer and vacuum chamber) is positioned relatively high above the ground, giving rise to low frequency vibrational resonances of the entire system. Therefore, the hexapod system has a high rigidity and acts to reduce the vibrational amplitude. Additionally, a heavy bottom block shifts the center of mass below the chamber, thereby stabilizing the whole system.

\section{REACTION ENVIRONMENT}

In order to reach into a regime where catalytic reactions can be performed under realistic conditions of several bars, a novel design of the reaction region was implemented. In the following, we denote the volume in which the pressure is increased locally as a high-pressure environment, noticing that one can vary the pressure between UHV conditions and above 1 bar within this region. The conceptual design does not constitute a pressure cell but instead integrates into the front cone of the electron analyzer. In fact, a gas outlet was integrated in the custom front cone as described hereafter.

\section{A. Front cone design}

In the virtual cell design, a flow of premixed gases is directed onto the sample surface to create a local high-pressure environment (Fig. 2). This concept is integrated into a redesigned electron analyzer front cone, which is fully interchangeable with the 

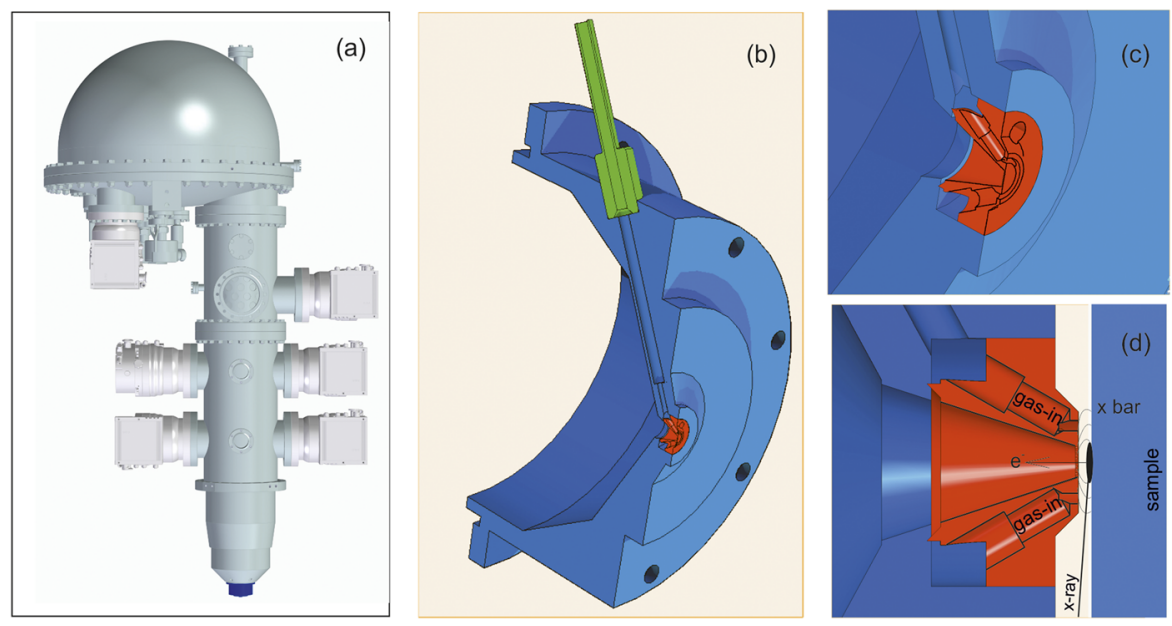

FIG. 2. The build-up of the high-pressure environment is done by integrating a gas feeding into the front cone of the electron analyzer as shown in (a). (b) and (c) show the front cone with different magnifications. The gas is guided through the adapted front cone and leaves the device through a circular symmetrical channel. (d) shows details around the virtual cell. Positioning the sample in close proximity, a cushion of high pressures is formed at the apex of the front cone at the sample surface. Grazing incidence x-rays are used to excite the system and scatter the photoelectrons into the electron analyzer.

standard model from Scienta-Omicron. The gas inlet [shown in green in Fig. 2(b)] is connected with standard fittings. The circular gas outlet [shown in red in Figs. 2(c) and 2(d)] is machined from a single titanium workpiece. It directs a gas flow onto the sample and creates a circularly symmetric high-pressure gas cushion at the sample surface. This cushion has an extension of $\sim \varnothing 2.5 \mathrm{~mm}$ and a variable thickness of about $0-100 \mu \mathrm{m}$, representing a local highpressure environment only (see also Sec. V C). We call this a virtual cell as the gas molecules are not trapped.

The x-ray beam enters the high-pressure environment under grazing incidence with respect to the sample [Fig. 2(d)]. Total reflection conditions at incidence angles of typically below $\sim 1^{\circ}$ increase the surface sensitivity of the measurements.

A $70 \mu \mathrm{m}$-thin Ti foil separates the high-pressure environment in the virtual cell from the first differential pumping stage of the electron analyzer. The design of this foil is considered a key element in the development of this instrument. The foil is perforated with micrometer-sized holes of equal diameter that allow high electron transmission rates and simultaneously separate the highpressure environment from the vacuum system. Since photoelectrons also scatter at gas molecules within the holes, the foil thickness was reduced as much as possible without affecting mechanical stability. Such condition was obtained for a foil thickness of $70 \mu \mathrm{m}$.

\section{B. Aperture design}

Instead of using one single aperture, several evenly spaced apertures, made by laser drilling, match the extended footprint of the $\mathrm{x}$-ray beam on the sample surface in grazing incidence. Figure 3 shows a light optical microscopy image of the front cone tip where the gas outlet is seen as a white ring and the apertures are centered. For the experiments, we produced a set of front cones with aperture diameters of $10,20,30,50$, and $100 \mu \mathrm{m}$. In order to avoid cross talk between individual apertures, the distance is chosen to be approximately 3 times the aperture diameter. This estimation is based on the work by Gronych et al. ${ }^{43}$ However, recent simulations show that the inter aperture distance can be reduced much further (see description in Sec. V C).

\section{Sample manipulation}

The sample is mounted on a separate hexapod positioning system (Symetrie, NanoPos) allowing for precise manipulation at the measurement position with step sizes down to $10 \mathrm{~nm}$ in the $\mathrm{X}, \mathrm{Y}$, and $\mathrm{Z}$ directions and $1 \mu \mathrm{rad}$ in the $\mathrm{Rx}, \mathrm{Ry}$, and Rz directions, respectively. The motion toward and away from the front cone is extended by a linear translation stage (Newport, 9067-X-M) giving an additional $25.4 \mathrm{~mm}$ travel range. The manipulator was specifically designed to match the application of high precision positioning and reduced vibrational amplitude.

The virtual cell approach allows for simple manipulation of the sample inside the vacuum, where sample positions associated with sputtering, annealing, etc., can easily be reached.

\section{Distance measurement}

A calibrated long-distance microscope with working distance $184 \mathrm{~mm}$ enables the measurement of the sample-to-aperture distance. It combines a telecentric lens (SILL TZM-CCS), with
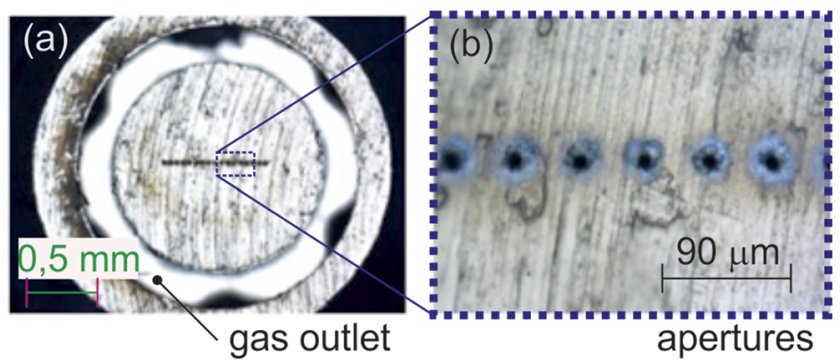

FIG. 3. (a) Light optical microscopy image of the front cone apex. The gas can exit the device through the ring-channel (white) creating a localized high-pressure cushion at the sample surface. The photoelectrons enter the electron analyzer through a set of micrometer-sized apertures arranged in line to match the footprint of $x$-rays on the sample surface. (b) Magnified view of the aperture array. In this model, the laser-drilled apertures have a diameter of $10 \mu \mathrm{m}$ and the distance between the individual apertures is $45 \mu \mathrm{m}$. 
$4 \times$ magnification and a DALSA Genie monochromatic camera with a detector pixel size of $3.45 \mu \mathrm{m}$. Image contrast is enhanced by a green light-emitting diode integrated in the camera objective. Depending on lightning and alignment, a resolution of $\sim 3 \mu \mathrm{m}$ is currently achieved.

\section{E. Sample heating}

The instrument is designed for flat hat shaped single crystal samples with laser heating from the backside. This allows XPS measurements without interference by magnetic or electric fields even in corrosive gas atmospheres. The temperature is measured using nonmagnetic $\mathrm{N}$-type thermocouples attached to the outer rim of the sample. Ni-contaminations stemming from the thermocouples could not be detected as verified by XPS and electron microscopy.

With a combination of liquid $\mathrm{N}_{2}$ cooling and laser heating, controlled heat ramps of up to $3^{\circ} \mathrm{C} / \mathrm{s}$ can be achieved in the entire temperature range from -150 to $+950^{\circ} \mathrm{C}$.

As the reactive gases flow across the sample surface, the gas will absorb energy and equilibrates with the sample temperature. Under reaction conditions, temperatures of up to $500{ }^{\circ} \mathrm{C}$ have been reached.

\section{F. Gas purity}

The continuous feeding of gases at higher pressures forces contaminating gas molecules, originating from the vacuum chamber, out of the high-pressure environment. The contamination will therefore only depend on the inevitable contamination from the feed gas as shown by Johansson et al. ${ }^{44}$ The largest fraction of gas molecules leaves the high-pressure environment to the side and expands into the surrounding vacuum vessel where they are pumped off.

\section{GAS FEEDING AND VACUUM SYSTEM}

Gases need to be premixed in a predefined ratio before they reach the high-pressure environment. For this purpose, we developed a gas mixing system capable of mixing 5 different gases simultaneously (see Fig. 4). Gases are supplied from gas cylinders and enter the experimental hutch via several meters of piping. Inside the hutch, the gas line pressure is stabilized to 5 bars at the point of use (POU) panel. Bronkhorst mass flow controllers (type FS-201CV) control the flow of each individual gas. The flow rate may be chosen between 0.16 and $10 \mathrm{~L}_{n} / \mathrm{min}$ with an accuracy of $\pm 0.5 \%$ of the full scale. Following the flow controllers, the gases are mixed in a small volume chamber and then guided through flexible hoses into the gas dosing system. Ni carbonyl formation during CO dosing is minimized by $\mathrm{Cu}$ piping and a separate carbonyl trap placed as close as possible to the instrument, right before the gas mixing system. Check valves and pressure relief valves are used to provide the necessary gas safety. In addition, we have implemented automatic software routines that shut off gas flow in case flammability limits are exceeded for $\mathrm{CO}+\mathrm{O}_{2}$ and for $\mathrm{H}_{2}+\mathrm{O}_{2}$ mixtures.

Once the gas passed the interaction region, it expands into the vacuum chamber and is pumped by the vacuum system of the instrument.

This consists of a total of 7 Pfeiffer Hi-Pace 300 turbo pumps, backed with a set of multistage root pumps (Kashyiama, NeoDry) of different pumping capacities. In order to reach a high vacuum regime, the main chamber is pumped with a tandem of turbo and a backing pump connected in parallel. During high-pressure experiments, where a large amount of gas flows through the system, the turbo pump is by-passed and the chamber is pumped only with two backing pumps, each with the capacity of $60 \mathrm{~m}^{3} / \mathrm{min}$. At a pressure exceeding 1 bar at the high-pressure environment, the pressure in the main chamber reaches $5-10 \mathrm{mbar}$ and the pressure at the detector is maintained below $5 \times 10^{-6}$ mbar. The usage of a virtual cell with basically zero volume allows switching of the gases at the sample quasi instantaneously with time scales that are only determined by the mass flow controllers and the piping structure.

\section{PRESSURE CALIBRATION}

\section{A. Method description}

A precise determination of the pressure in the high-pressure environment by direct measurement is complicated since it is generated only locally. It is not possible to introduce a physical pressure gauge into the gap between sample and cone due to space restrictions. Here, we describe a method to measure the pressure via the front cone aperture.

We continuously monitor the pressure in the first differential pumping section of the analyzer as we backfill the main chamber. Thus, a calibration curve is obtained which can be used to calculate the pressure in the high-pressure environment in the main chamber based on the first differential pumping stage gauge readings. We are aiming for accurate determination of the pressure in the high-pressure environment. Therefore, a gas type independent piezogauge is placed in the main chamber for calibration. It is a combined piezo/pirani gauge (Pfeiffer, RPT $200 \mathrm{~PB}$ ). The piezogauge has a full-scale accuracy of $\pm 0.3 \%$.

The change in the main chamber pressure results in a pressure response in the first differential pumping section. This response needs to be reproducible but not accurate. The pressure gauge in the differential pumping stage is a wide-range digital Pirani/BayardAlpert gauge (Pfeiffer, HPT $200 \mathrm{~PB}$ ) with a repeatability of $\pm 2 \%$. Calibration measurement must be carried out individually for different gases, since mobility and detection efficiencies are gas type dependent. For pressures below 1 bar, the calibration is performed by pressurizing the main vacuum chamber. For the calibration of pressures above 1 bar, a dedicated pressure cell is attached to the front cone. Examples of the obtained pressure calibration curves are shown in Fig. 5.

The datasets for $\mathrm{O}_{2}$, obtained by backfilling the main chamber, fit with the results from the pressure cell (blue circles). In fact, our tests show that one can extrapolate the data collected for pressures below 1 bar to higher values.

The change in the slope of the measurement for He corresponds to the switching pressure of the Bayard-Alpert pressure gauge in the first differential pumping stage. This effect is seen in all gas-types but is more pronounced for light gases such as $\mathrm{He}$ and $\mathrm{H}_{2}$.

As the pressure in the first differential pumping stage is dependent on the type of the pumps, aperture size and possible clogging of the micrometer sized holes, the pressure calibration is done in connection with each experiment individually. 


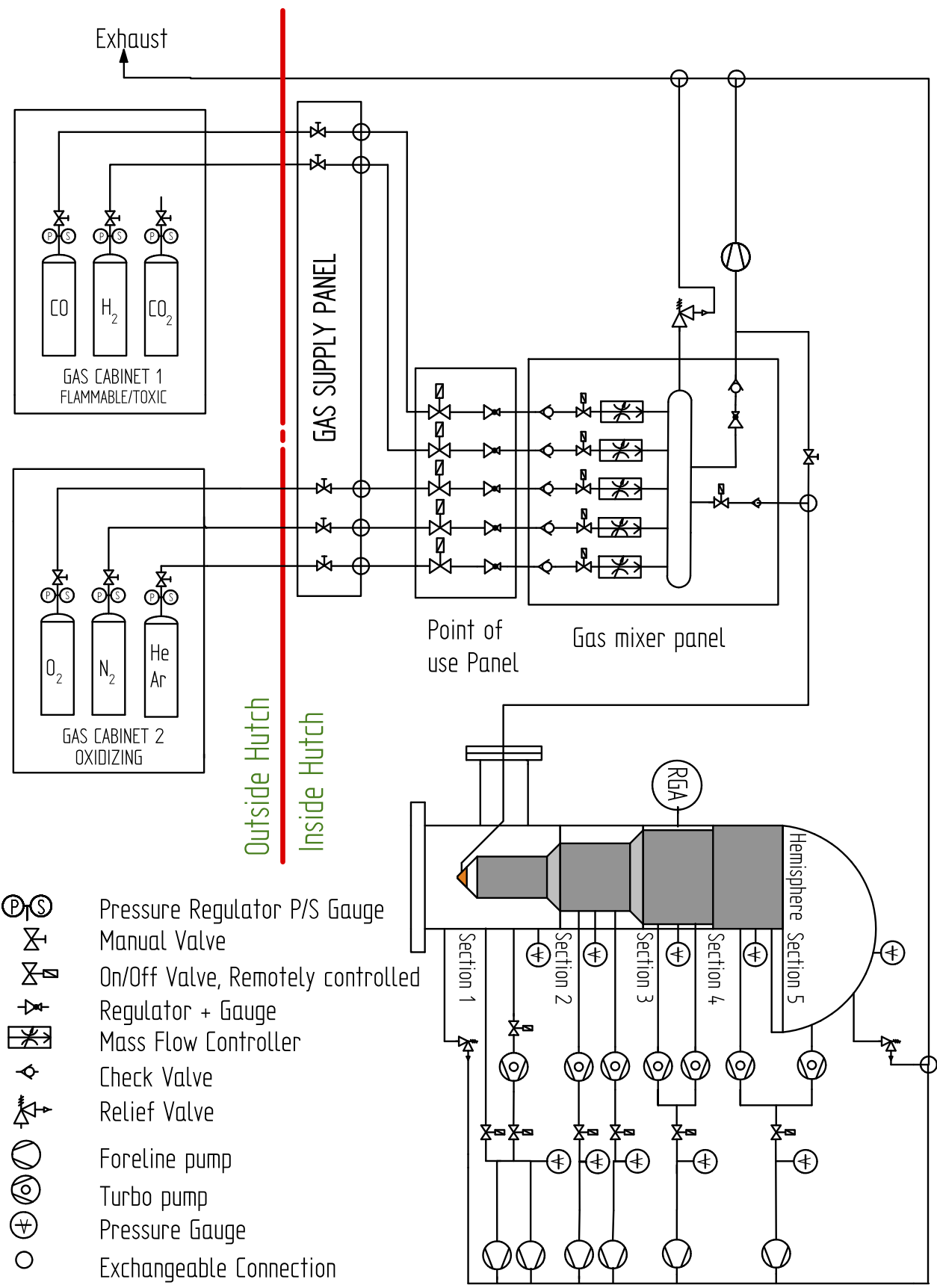

FIG. 4. In the working environment, the gas cabinets are placed outside the experimental hutch and the gas is guided through $1 / 4$ in. stainless steel pipes into the room. The gas-mixing is done fully remotely with a PC situated in a control room using mass-flow controllers and LabView programs. During experiments, most of the gas is pumped away through the main vacuum chamber (section 1) and only a little fraction leaves through the differential pumping of the electron analyzer (sections $2-5$ ).

\section{B. Flow regimes}

The amount of molecules passing the aperture depends on the gas flow regime. We ensure that both the calibration and the actual measurements are done in the same flow regime, which can be estimated using the Knudsen number $K n .^{23} \mathrm{Kn}$ relates the typical dimension $L$ of a chamber or component with the MFP of the gas molecules via $K n=M F P / L$. If the MFP of a gas molecule is short in comparison with the chamber's characteristic dimension, the gas is in the continuum flow regime, which is expressed as $K n<1$. 


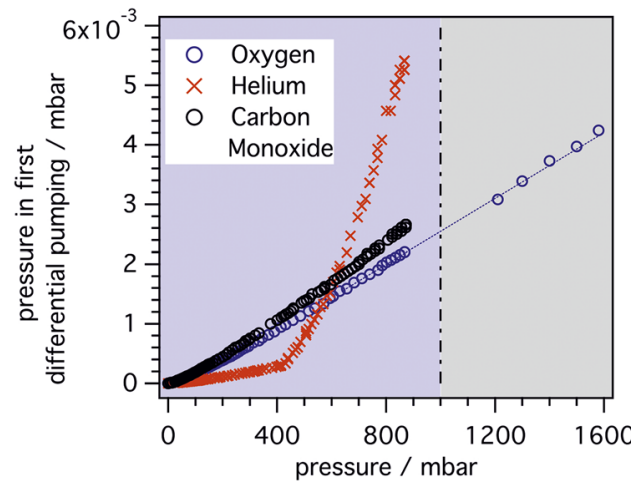

FIG. 5. Pressure calibration curve: the pressure in the first differential pumping stage of the electron analyzer is monitored as a dependence of pressure in before the aperture. Below $1000 \mathrm{mbar}$, the pressurizing can be done in the main chamber, at pressures exceeding 1000 mbar a pressure cell needs to be put on top of the front cone. The pressure in the two regions fits well with each other.

At a typical pressure regime of $300 \mathrm{mbar}$ at our sample, the MFP for $\mathrm{H}_{2}$ is $3.8 \times 10^{-7} \mathrm{~m}$ and for $\mathrm{CO}_{2} 1.3 \times 10^{-7} \mathrm{~m}$. Relating this to the sample-to-aperture distance which is on the order of the diameter of the aperture, i.e., $30 \mu \mathrm{m}$, we get $\mathrm{Kn}=0.013$ for $\mathrm{H}_{2}$ and 0.004 for $\mathrm{CO}_{2}$. This indicates that the usage of the virtual cell does not change the flow regime and supports the validity of the measurement. It should be noted that common pressure distribution calculations assume flow conditions with $K n \geq 1$. Therefore, previously presented calculations ${ }^{22,23}$ are not applicable for our instrument; however, we assume that the general trends are still valid. For example, Kahk et al. ${ }^{22}$ showed through numerical calculations that the sample-to-aperture distance can be reduced at higher pressures.

\section{Simulation results}

Finite element simulations were performed to gain a better understanding of the pressure build-up in the virtual cell design. Particularly, questions around the homogeneity of pressure buildup on the sample surface and the possible cross talk between the individual apertures can only be addressed from a theoretical side.

Finite-element calculations are performed on a mesh that is generated in the space between the frontcone and the sample. Due to symmetry reasons, only $1 / 4$ of the volume is simulated.

Figure 6(a) shows the calculated pressure distribution of the volume that is occupied by the gas molecules. Cold (blue) colors correspond to low pressure and hot (red) colors to high pressure.

At the gas inlet, a feed of $4 \mathrm{l} / \mathrm{min}$ of $\mathrm{N}_{2}$ gas is assumed and a pressure build-up is observed at the sample surface. At the outflow [outer rim of the blue area in Fig. 6(a)], the calculation is constrained to a pressure of 9 mbar and at the center of the individual apertures a pressure of $1 \times 10^{-3} \mathrm{mbar}$ is assumed. These boundary conditions have been carefully chosen in connection with earlier simulations. ${ }^{22}$ They correspond to a worst case scenario, and the experiment should therefore be favorable. The zoomed image (center) shows details around the apertures. The sample-to-aperture distance is fixed to $30 \mu \mathrm{m}$.
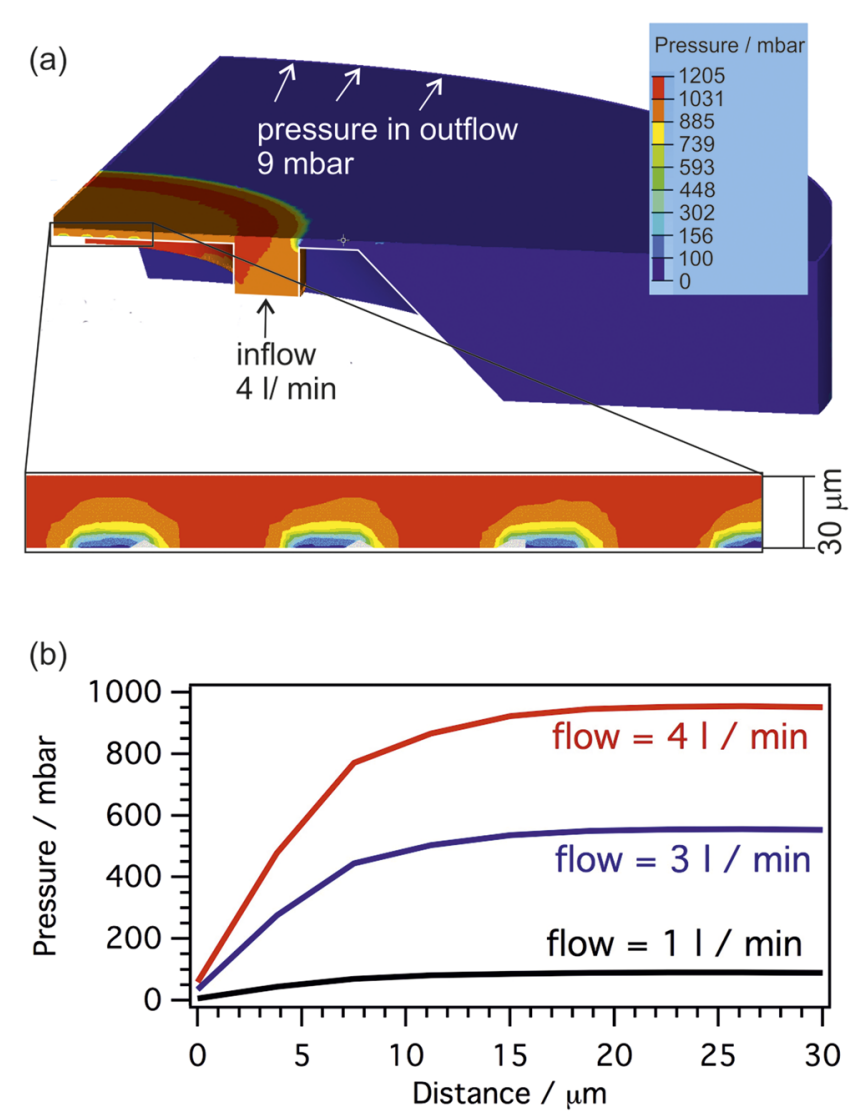

FIG. 6. Simulation of the pressure build-up in the virtual cell. (a) The pressure is simulated in a $1 / 4$ area of the gap between sample and front cone with a gap distance of $30 \mu \mathrm{m}$ and an aperture diameter of $30 \mu \mathrm{m}$. As the gas is fed with 4 $\mathrm{l} / \mathrm{min}$, the pressure is built up at the sample surface. Most of the gas is leaving through the sides, expanding rapidly wherefore a fast pressure drop is noticed. (b) Pressure as a function of distance and gas flow. $90 \%$ of the sample pressure is reached already at a distance of $10.8 \mu \mathrm{m}$ corresponding to $36 \%$ of the aperture diameter.

The blue region represents the area where the gas expands toward the side and a rapid pressure drop occurs. In Fig. 6(b), the pressure is given as a function of distance from the aperture for three different flows. We note that (i) for a flow of $4 \mathrm{l} / \mathrm{min}$, the pressure quickly increases in the direction of the sample surface. Already at a distance of $10.8 \mu \mathrm{m}$ from the aperture hole, $90 \%$ of the pressure at the sample surface is reached. This corresponds to a distance of $36 \%$ of the aperture diameter. $99 \%$ of the surface pressure is reached at a distance of $18.1 \mu \mathrm{m}$ corresponding to $60 \%$ of the aperture diameter. A decrease in the flow from 4 to $1 \mathrm{l} / \mathrm{min}$ results only in a minor change of $0.1 \mu \mathrm{m}$ for the $90 \%$ threshold. These results have major implications on how an experiment can be conducted for any future high-pressure XPS applications. The quick adjustment of the pressure in this pressure- and flow regime suggests that one can conduct XPS experiments at distances smaller than 1 times the aperture diameter, which is preferred for the high-pressure XPS experiments due to reduced electron scattering. Therefore, we believe that it paves a way of conducting experiments at pressures exceeding 1 bar. 
(ii) The fast change in pressure parallel to the surface highlights that the aperture-to-aperture distance can be reduced in future front cone designs, thereby increasing the electron yield. (iii) The pressure distribution on the sample surface is homogeneous and not affected by the presence of apertures. (iv) The underlying assumptions of the calculations have been tested against variations of the boundary conditions and show negligible influence on the pressure distribution.

\section{RESULTS}

The system performance was tested on single crystal $\mathrm{Rh}(111)$ and $\mathrm{Cu}(211)$ surfaces in several synchrotron experiments. $\mathrm{Rh}(111)$ was cleaned following standard recipes by repeated cycles of $\mathrm{Ar}^{+}$ ion sputtering at $3 \mathrm{keV}$ and annealing in vacuum to $950^{\circ} \mathrm{C}$ at a rate of $3{ }^{\circ} \mathrm{C} / \mathrm{s}$. $\mathrm{Cu}(211)$ was likewise cleaned by sputter and annealing cycles. During the experiment, the crystal is aligned parallel to the apex of the front cone using the long-distance microscope as described in Sec. III D. Unless otherwise stated, a self-designed front cone as described in Sec. III with an aperture diameter of $30 \mu \mathrm{m}$ was used. The experiments have been performed at beamline P22 of the Petra III ring at DESY, Hamburg, using the Si(111) crystals in the monochromator and photon energies between 3.5 and $3.8 \mathrm{keV}$. In this energy regime, $\sim 10^{13} \mathrm{ph} / \mathrm{s}$ were provided with a focus of $\sim 150 \times 200 \mu \mathrm{m}^{2}$ (horizontal $\times$ vertical) for the Rh experiments and $\sim 20 \times 50 \mu \mathrm{m}^{2}$ for the $\mathrm{Cu}$ experiments. The photon energy bandwidth provided by the beamline is $\sim 430 \mathrm{meV}$ in this energy regime.

\section{A. Grazing incidence XPS}

Grazing incidence XPS measurements are performed by rotating the whole instrument around the single crystal surface plane while keeping the sample surface parallel to the front cone apex. In order to determine the angle of incidence, a fluorescent screen is positioned downstream of the instrument. A sample, half-cutting the photon beam, partially reflects the light to the screen. The splitting between the reflected and direct beam is a measure of the angle of incidence and allows for a precise alignment of the instrument.

Decreasing of the incidence angle below the critical angle of total reflection results in enhanced surface sensitivity. Figure 7 shows an example of Rh3d and $\mathrm{O} 1 s$ spectra taken at $-100^{\circ} \mathrm{C}$ from a CO covered surface of $\mathrm{Rh}(111)$ at $1^{\circ}$ and $0.3^{\circ}$ incidence angle, i.e., above and below the critical angle of total reflection, respectively. The spectra were normalized to the intensity of the Rh $3 p_{1 / 2}$ component after subtraction of the Shirley type background.

The O1s signal increased by a factor of 5 for the surface sensitive measurement. The effect is mainly due to an intensity increase in the CO signal, as the bulk signal is affected very little by the change in angle. This demonstrates the surface sensitivity of grazing incidence XPS, and the adsorbates on the surface can be detected despite working with hard $\mathrm{x}$-rays. The enhanced surface sensitivity by grazing incidence XPS makes single-crystal and flat metal sample studies favorable. However, we expect that industrial catalyst materials like powders pressed into pellets also become accessible with the virtual cell approach if the corrugation is below a few micrometer. For special cases, like nanoparticles on single crystals, one expects to still

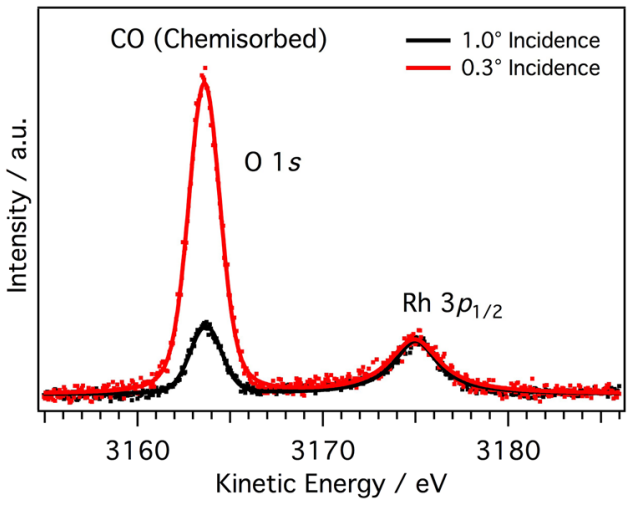

FIG. 7. Grazing incidence XP spectra of the $01 s$ and $\mathrm{Rh} 3 p_{1 / 2}$ region taken at 1 (black) and $0.3^{\circ}$ (red) grazing incidence angle on $\mathrm{CO}$ covered $\mathrm{Rh}(111)$. The peaks have been background-subtracted and normalized to the same peak height of $\mathrm{Rh}$ $3 p_{1 / 2}$. The photon energy was tuned to $3.7 \mathrm{keV}$. The sample was kept at $-100^{\circ} \mathrm{C}$ during the experiment.

be able to gain from grazing incidence due to the total reflection condition of the below lying bulk material in a similar fashion as performed with larger molecules on surfaces described by Drube. ${ }^{45}$ The instrument capabilities also open up the possibility of performing $\mathrm{X}$-ray standing wave experiments. ${ }^{46-48}$

\section{B. High pressure XPS}

First tests of high pressure performance of the instrument were performed in helium. The electron MFP in this gas is longer as compared to $\mathrm{CO}$ or $\mathrm{CO}_{2}$ allowing higher pressure regimes. However, since $\mathrm{He}$ is scientifically less relevant, the discussion will turn subsequently to more realistic systems using mixtures of $\mathrm{CO}$ and $\mathrm{H}_{2}$ as well as $\mathrm{CO}$ and $\mathrm{O}_{2}$. Finally, we will show first results for adsorbate carbon species under realistic conditions.

XP spectra were taken at a sample-to-aperture distance of 20 $30 \mu \mathrm{m}$. The pressure was adjusted by changing the gas flow and calibrated as described in Sec. V. All spectra were acquired at room temperature in sweep mode. Figure 8 shows core level signals of $\mathrm{Cu}$ taken in $\mathrm{He}$ at a photon energy of $3750 \mathrm{eV}$. The analyzer was operated at a pass energy of $100 \mathrm{eV}$ and a curved slit of $0.8 \mathrm{~mm}$ was chosen, which corresponds to an instrumental resolution of $200 \mathrm{meV}$. Systematically changing the pressure, we could measure $\mathrm{XP}$ spectra at pressures above 2.5 bars. For better visibility, selected spectra are also shown in Fig. 9 with different normalization. The total integration time was below $15 \mathrm{~min}$. In Fig. 8, all spectra have been normalized to the same intensity at $2820 \mathrm{eV}$ kinetic energy and subsequently a Shirley type background was subtracted. In Fig. 9, the data have been normalized to the peak intensity of the $\mathrm{Cu} 2 p_{3 / 2}$ line and a fit was superimposed. The signal is composed of two partially resolved peaks at the $\mathrm{Cu} 2 p_{1 / 2}$ position, which vary in intensity. The feature arising at the lower kinetic energy side denoted as (a) gets relatively more pronounced with higher pressure. Applying a fit with two Voigt components, one can observe a linear trend of the fractional peak areas of feature (a) to feature (c), i.e., the $\mathrm{Cu} 2 p_{3 / 2}$ component. At the highest pressure of 2560 mbar, feature (a) has $80 \%$ of the area of $\mathrm{Cu} 2 p_{3 / 2}$. The feature can be understood in terms 


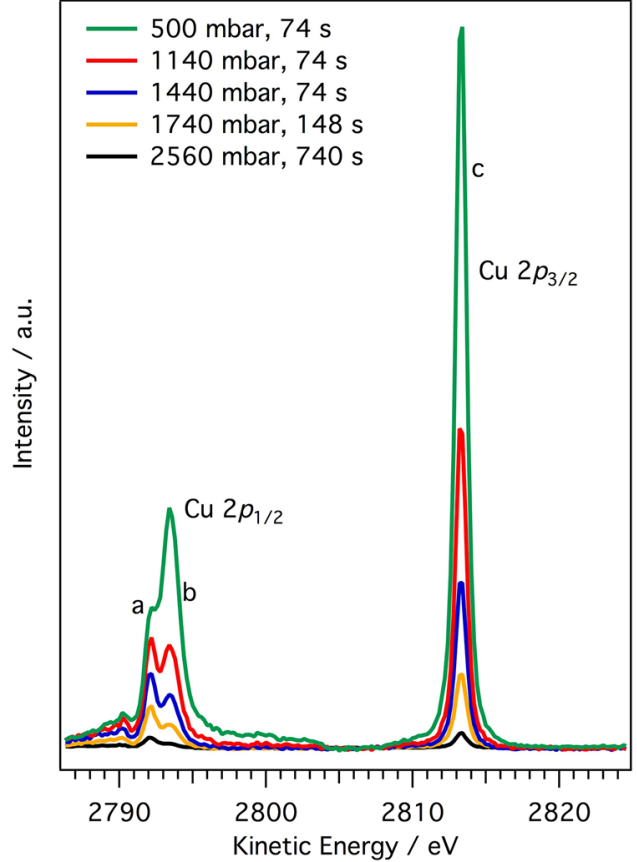

FIG. 8. Pressure-dependent $\mathrm{Cu} 2 p$ core level measurement at a sample-to-front cone distance of $\sim 20 \mu \mathrm{m}$ and a grazing incidence angle of $1.3^{\circ}$. The datasets were acquired at room temperature.

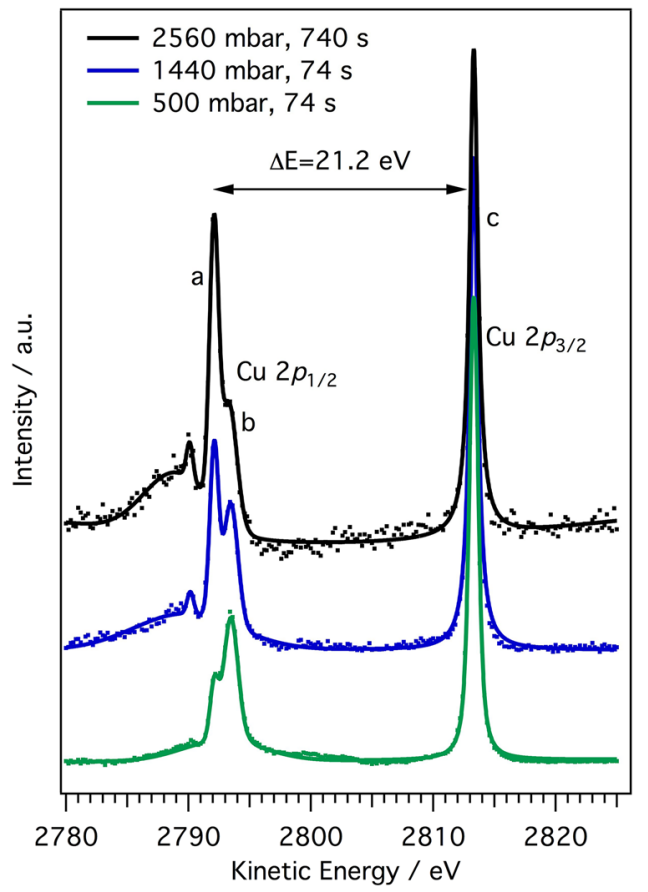

FIG. 9. Same dataset as in Fig. 8 but normalized to the same peak intensity of $\mathrm{Cu}$ $2 p_{3 / 2}$. The additional feature at the low kinetic energy side of the $\mathrm{Cu} 2 p_{1 / 2}$ is due to electron energy loss processes exciting the He from the $1 \mathrm{~s} 2$ to $1 \mathrm{~s} 12 \mathrm{p} 1$ state. of an electron energy loss process where the electrons are inelastically scattered by the helium gas, where $\mathrm{He}$ gets excited from $\mathrm{He}$ $(1 s 2)$ to $\mathrm{He}(1 s 12 p 1)$ giving rise to a loss of $21.2 \mathrm{eV}$, as indicated in Fig. 9. ${ }^{49}$

Performing a line-shape analysis of the $\mathrm{Cu} 2 p_{3 / 2}$ peak, we do not observe a spectral broadening as a function of pressure within the error of the peak fitting routine. This indicates that the gas has minor contribution to the peak shape except for the distinct loss features and a general increase in background. This is in line with previous APXPS measurements. ${ }^{42,50}$

Figure 10 shows the same region on $\mathrm{Cu} 2 p$ but in a mixture of $\mathrm{H}_{2}$ and $\mathrm{CO}$ at a ratio of 3:1. All data have been taken at room temperature.

The red spectrum is taken in a submillibar regime and shows two pronounced peaks corresponding to $\mathrm{Cu} 2 p_{1 / 2}$ and $\mathrm{Cu} 2 p_{3 / 2}$. The black curve is measured at a total pressure of $750 \mathrm{mbar}$ and is enhanced by a factor of 45 for better visibility. In addition to the $\mathrm{Cu} 2 p$ states, two more features appear that are $\sim 12.8$ and $8.5 \mathrm{eV}$ distanced from the $\mathrm{Cu} 2 p_{3 / 2}$. These features correspond to the electron energy loss process from excitation of the $\mathrm{H}_{2}$ molecules $(12.8 \mathrm{eV})$ and $\mathrm{CO}$ molecules $(8.5 \mathrm{eV})$ as can be verified by comparison to electron energy loss spectra (EELS). ${ }^{49,51}$ The integration time of the spectra taken at 750 mbar was $5 \mathrm{~min}$, showing the excellent performance of the instrument. Unlike in traditional XPS or APXPS, the EELS features that are presented here are very pronounced due to the higher pressure. As the loss features are characteristic for the gas type, it opens for the possibility to follow the formation of reaction products in the gas phase with XPS.

To complement this, spectra for the $\mathrm{CO}$ oxidation reaction on a $\mathrm{Rh}$ single crystal were acquired, which is an important reaction in car exhaust catalysis. The data show that the Rh $3 d_{5 / 2}$ level can be followed up to a pressure of $1280 \mathrm{mbar}$ (see Fig. 11). For the experiment, a grazing incidence angle of $0.8^{\circ}$ was used and the temperature was kept at $150{ }^{\circ} \mathrm{C}$. Integration times are indicated in the graph.

Next, we turn our focus to carbon species on top of surfaces. Figure 12 shows $\mathrm{C} 1 s$ spectra taken on carbon contaminated $\mathrm{Cu}(211)$

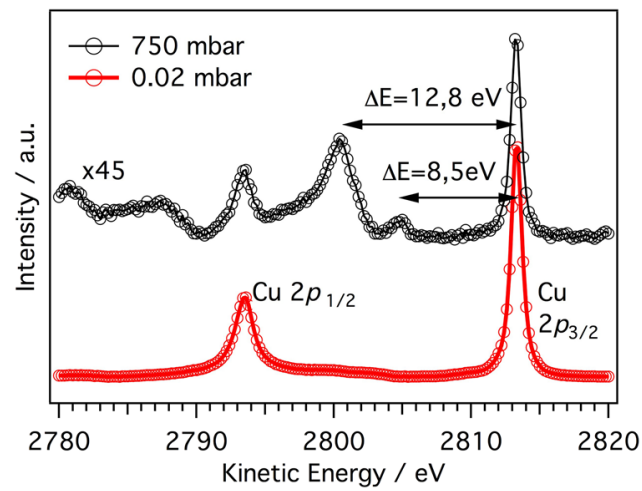

FIG. 10. Cu $2 p$ XP spectra taken in a submillibar regime (red) and at $750 \mathrm{mbar}$ mixture of $\mathrm{H}_{2}$ and $\mathrm{CO}$. The loss of $12.8 \mathrm{eV}$ corresponds to the electron loss in hydrogen, and the loss of $8.5 \mathrm{eV}$ corresponds to the loss for $\mathrm{CO}$. The data have been taken at room temperature. 


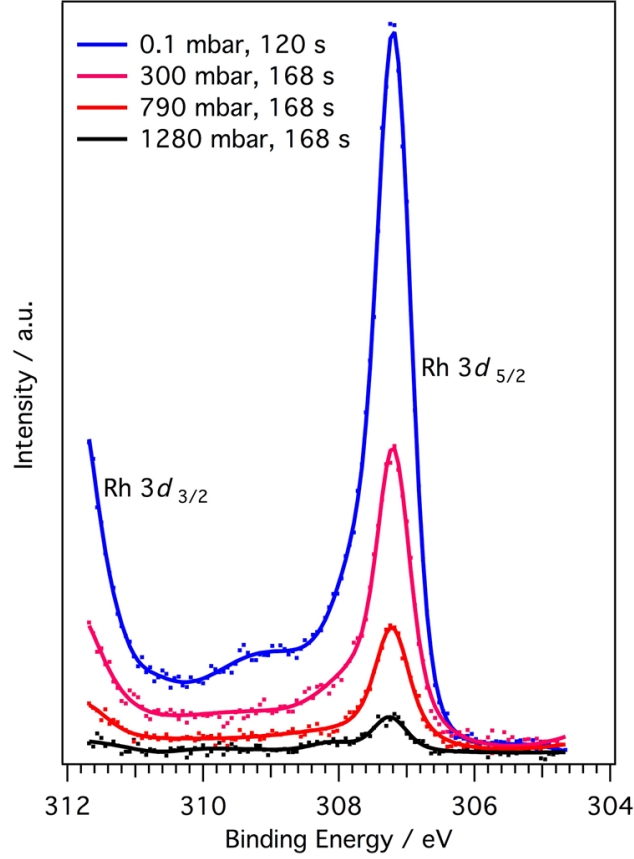

FIG. 11. Rh $3 d_{5 / 2}$ spectra taken in the gas mixture of $\mathrm{He}: \mathrm{CO}: \mathrm{O}_{2}$ at a ratio of 3:1:1. The peak intensity is shown as a function of pressure at a constant temperature of $150^{\circ} \mathrm{C}$

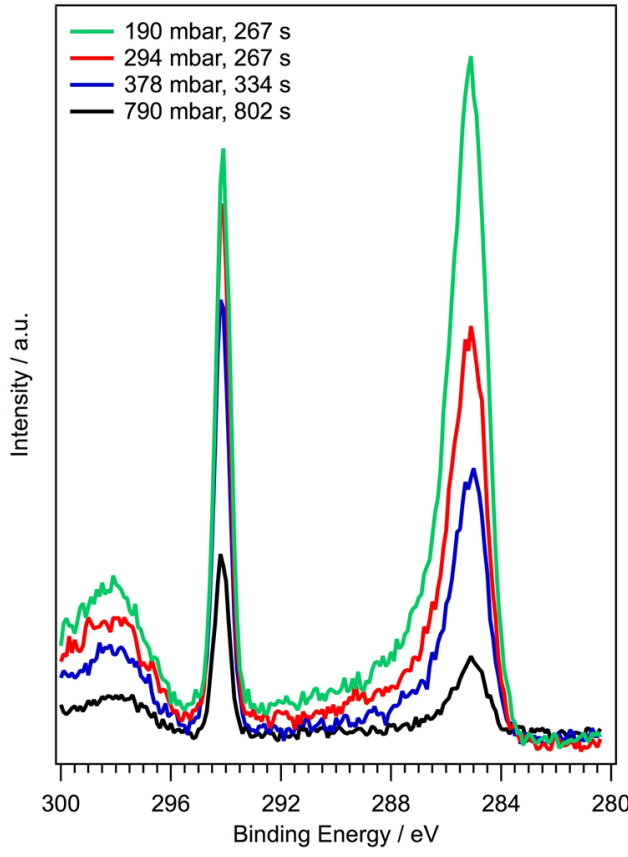

FIG. 12. XP spectra of a carbon contaminated $\mathrm{Cu}(211)$ surface in a mixture of $\mathrm{H}_{2}: \mathrm{CO}_{2}=4: 1$ at $100^{\circ} \mathrm{C}$. The peak at $\sim 294 \mathrm{eV}$ corresponds to gas phase $\mathrm{CO}_{2}$. The $\mathrm{C} 1 \mathrm{~s}$ signal at $285 \mathrm{eV}$ is visible up to pressures of $790 \mathrm{mbar}$. The EELS feature due to electron scattering is found $\sim 12 \mathrm{eV}$ below. under realistic conditions with gas mixtures of $\mathrm{CO}_{2}: \mathrm{H}_{2}=1: 4$. The $\mathrm{CO}_{2}$ gas phase peak appears at $\sim 294 \mathrm{eV}$. The feature between 295 and $300 \mathrm{eV}$ is due to electron energy loss processes where electrons get scattered mainly by $\mathrm{H}_{2}$ molecules in the gas phase. The $\mathrm{C} 1 s$ feature at $285 \mathrm{eV}$ is measured up to a pressure of 790 mbar with integration times below $15 \mathrm{~min}$. The spectra were taken at a grazing incidence angle of $0.8^{\circ}$.

Expectedly, the investigation of surface adsorbates around the $\mathrm{C} 1 s$ core level results in reduced count rates in comparison to spectroscopy on metallic bulk states. However, the usage of grazing incidence $\mathrm{x}$-rays allows for enhancement of the surface signal and therefore allows us to study adsorbates on surfaces.

\section{Temperature programmed techniques}

A quadrupole mass spectrometer (Hiden, HAL/3F RC 301 PIC system) positioned alternatively at the first, second, or third differential pumping stage of the electron analyzer was used to follow the reaction products. This is exemplified using a $\mathrm{Rh}(111)$ single crystal following the formation of $\mathrm{CO}_{2}$ from $\mathrm{CO}+1 / 2 \mathrm{O}_{2}$. The experiment was conducted in a mixture of $\mathrm{He}, \mathrm{CO}$, and $\mathrm{O}_{2}$ with the ratio of $\mathrm{He}: \mathrm{O}_{2}: \mathrm{CO}=7.5: 3.5: 1$ at a total pressure of $\sim 1.4$ bars (see Fig. 13). The front cone was self-designed as shown in Sec. III and had aperture diameters of $10 \mu \mathrm{m}$. The sample-to-aperture distance was about $20 \mu \mathrm{m}$, and the total gas flow was $2.4 \mathrm{l} / \mathrm{min}$. The temperature was ramped following the dashed black line with $2.5^{\circ} \mathrm{C} / \mathrm{s}-$ $500{ }^{\circ} \mathrm{C}$. As it reaches the reaction onset at $330^{\circ} \mathrm{C}, \mathrm{CO}$ and $\mathrm{O}_{2}$ start to get consumed and $\mathrm{CO}_{2}$ is formed. The variation in signal intensity is best seen at $\mathrm{t}=4 \mathrm{~min}$ on the $\mathrm{O}_{2}$ signal, which originates from thermal expansion of the sample holder. As the sample thermally expands, the sample to front cone gap narrows and the pressure increases. This is counteracted by the hexapod positioning system and the signal drops again (min. 4.5). This experiment opens for combined measurements of temperature programmed reactions and XPS under realistic conditions up to $500^{\circ} \mathrm{C}$ probing the sample at the same area.

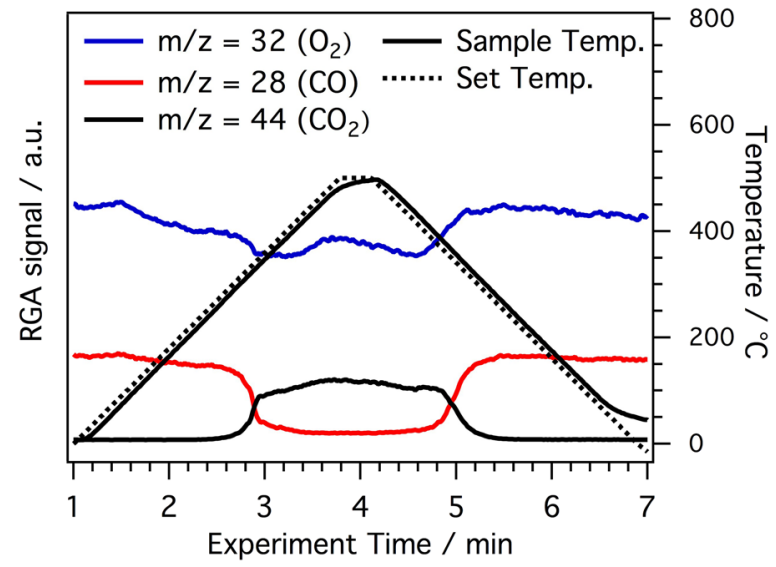

FIG. 13. Mass spectrometry signal of $\mathrm{m} / \mathrm{z}$ corresponding to $\mathrm{CO}$ (red), $\mathrm{O}_{2}$ (blue) and $\mathrm{CO}_{2}$ (black) and left axis. The single crystal temperature (dashed black and right axis) was ramped at a rate of $2.5^{\circ} \mathrm{C} / \mathrm{s}$. 


\section{CONCLUSION}

We have developed a new high-pressure XPS instrument that is dedicated to studies of catalytic reactions at pressures of multiple bars. The instrument performance builds on a newly developed virtual cell concept that allows pressure to be applied locally on the sample surface. Utilizing a high precision manipulator, the gap between front cone and sample can be controlled with micrometer precision, hence providing fine control of the local pressure at the surface. The use of hard x-rays enhances the MFP of electrons in the gas atmosphere. Synchrotron based grazing incidence photoelectron spectroscopy below the critical angle of reflection is used to enhance the surface contribution to the signal. Differential pumping of the analyzer is facilitated by an array of evenly spaced apertures aligned to best capture the footprint of $\mathrm{x}$-rays on the sample surface. This allows spectra at 2.5 bar He pressure with integration times below 15 min to be accumulated. The virtual cell concept allows the sample to be freely manipulated inside the vacuum chamber. The feeding gas is the sole contributor to contamination during gas experiments. The use of a virtual cell with basically zero volume allows for the exchange of gases quasi instantaneously. Our simulation results show that for the presented pressure regimes presented here, one can perform the experiment at sample-to-aperture distances below 1 times the aperture diameter with reduced scattering. At elevated pressures, EELS features become pronounced allowing us to identify the gas type in front of the sample. The instruments' capability to perform XPS at pressures exceeding 1 bar and control the temperature up to $500^{\circ} \mathrm{C}$ opens up for studies of industrially relevant catalytic reactions.

\section{ACKNOWLEDGMENTS}

This work was supported by the Swedish Research Council (Vetenskapsrådet VR), the Global Climate and Energy Project (GCEP) at Stanford University, the Knut and Alice Wallenberg (KAW) foundation, as well as the Swedish Foundation for strategic research (Stiftelsen för Strategisk Forskning, SSF) under Project No. ITM 17-0034. The authors would like to thank Rolf Helg and Bosse Barksäter for the manufacturing of parts as well as the technical division at fysikum (Department of Physics) at Stockholm University, Henrik Öström from Stockholm University, and Hirohito Ogasawara from the SLAC National Accelerator Laboratory, Stanford, and SUNCAT Center for Interface Science and Catalysis for discussions. We acknowledge DESY (Hamburg, Germany), a member of the Helmholtz Association HGF, for the provision of experimental facilities. The research was carried out at the P22 beamline of Petra III.

\section{REFERENCES}

${ }^{1}$ A. H. Tullo, Chem. Eng. News 96, 36 (2018); available at https://cen.acs.org/ content/dam/cen/97/30/WEB/globaltop50-2018.pdf.

${ }^{2}$ F. Schmidt, Basic Principles in Applied Catalysis (Springer-Verlag, 2004).

${ }^{3}$ A. Knop-Gericke, E. Kleimenov, M. Hävecker, R. Blume, D. Teschner, S. Zafeiratos, R. Schlögl, V. I. Bukhtiyarov, V. V. Kaichev, I. P. Prosvirin, A. I. Nizovskii, H. Bluhm, A. Barinov, P. Dudin, and M. Kiskinova, Adv. Catal. 52, 213 (2009).

${ }^{4}$ A. Nilsson, J. Electron Spectrosc. Relat. Phenom. 126, 3 (2002).

${ }^{5}$ C. Papp and H.-P. Steinrück, Surf. Sci. Rep. 68, 446 (2013).
${ }^{6} \mathrm{G}$. A. Somorjai and Y. Li, Introduction to Surface Chemistry and Catalysis (Wiley, 2010).

${ }^{7}$ G. Ertl, K. Helmut, S. Ferdi, and W. Jens, Handbook of Heterogeneous Catalysis, 2nd ed. (Wiley-VCH, 2008).

${ }^{8}$ H. Bluhm, M. Hävecker, A. Knop-Gericke, M. Kiskinova, R. Schlögl, and M. Salmeron, MRS Bull. 32, 1022 (2007).

${ }^{9}$ M. Salmeron and R. Schlögl, Surf. Sci. Rep. 63, 169 (2008).

${ }^{10}$ S. Kaya, H. Ogasawara, L. Å. Näslund, J. O. Forsell, H. S. Casalongue, D. J. Miller, and A. Nilsson, Catal. Today 205, 101 (2013).

${ }^{11}$ S. Axnanda, E. J. Crumlin, B. Mao, S. Rani, R. Chang, P. G. Karlsson, M. O. M Edwards, M. Lundqvist, R. Moberg, P. Ross, Z. Hussain, and Z. Liu, Sci. Rep. 5, 9788 (2015).

${ }^{12}$ Y. Takagi, T. Nakamura, L. Yu, S. Chaveanghong, O. Sekizawa, T. Sakata, T. Uruga, M. Tada, Y. Iwasawa, and T. Yokoyama, Appl. Phys. Express 10, 076603 (2017).

${ }^{13}$ M. Amati, M. Kazemian Abaneh, and L. Gregoratti, J. Instrum. 8, T05001 (2013).

${ }^{14}$ Y. Takagi, T. Uruga, M. Tada, Y. Iwasawa, and T. Yokoyama, Acc. Chem. Res. 51, 719 (2018).

${ }^{15}$ L. Trotochaud, A. R. Head, O. Karslıoğlu, L. Kyhl, and H. Bluhm, J. Phys. Condens. Matter 29, 053002 (2017).

${ }^{16}$ M. A. Brown, A. B. Redondo, I. Jordan, N. Duyckaerts, M.-T. Lee, M. Ammann, F. Nolting, A. Kleibert, T. Huthwelker, J.-P. Mächler, M. Birrer, J. Honegger, R. Wetter, H. J. Wörner, and J. A. Van Bokhoven, Rev. Sci. Instrum. 84, 073904 (2013).

${ }^{17}$ F. D. Ogletree, H. Bluhm, E. D. Hebenstreit, and M. Salmeron, Nucl. Instrum. Methods Phys. Res., Sect. A 601, 151 (2009).

${ }^{18}$ D. E. Starr, Z. Liu, M. Hävecker, A. Knop-Gericke, and H. Bluhm, Chem. Soc. Rev. 42, 5833 (2013).

${ }^{19}$ J. T. Newberg, J. Åhlund, C. Arble, C. Goodwin, Y. Khalifa, and A. Broderick, Rev. Sci. Instrum. 86, 085113 (2015).

${ }^{20}$ C. Arble, M. Jia, and J. T. Newberg, Surf. Sci. Rep. 73, 37 (2018).

${ }^{21}$ K. Roy, C. P. Vinod, and C. S. Gopinath, J. Phys. Chem. C 117, 4717 (2013).

${ }^{22}$ J. M. Kahk, I. J. Villar-Garcia, L. Grechy, P. J. K. Bruce, P. E. Vincent, S. K. Eriksson, H. Rensmo, M. Hahlin, J. Åhlund, M. O. M. Edwards, and D. J. Payne, J. Electron Spectrosc. Relat. Phenom. 205, 57 (2015).

${ }^{23}$ D. F. Ogletree, H. Bluhm, G. Lebedev, C. S. Fadley, Z. Hussain, and M. Salmeron, Rev. Sci. Instrum. 73, 3872 (2002).

${ }^{24}$ G. D. Danilatos, AIP Conf. Proc. 585, 924-932 (2001).

${ }^{25}$ C. Jeong, H. Yun, H. Lee, S. Muller, J. Lee, and B. S. Mun, Curr. Appl. Phys. 16, 73 (2016).

${ }^{26}$ J. Knudsen, J. N. Andersen, and J. Schnadt, Surf. Sci. 646, 160 (2016).

${ }^{27}$ J. Schnadt, J. Knudsen, J. N. Andersen, H. Siegbahn, A. Pietzsch, F. Hennies, N. Johansson, N. Mårtensson, G. Ohrwall, S. Bahr, S. Mähl, and O. Schaff, J. Synchrotron Radiat. 19, 701 (2012).

${ }^{28}$ L. Nguyen and F. F. Tao, Rev. Sci. Instrum. 87, 064101 (2016).

${ }^{29}$ G. Kerherve, A. Regoutz, D. Bentley, C. Hood, K. Feeley, S. Knight, A. Robson, C. Turner, N. Singh, J. Pontefract, J. Åhlund, J. M. Kahk, I. J. Villar-Garcia, and D. J. Payne, Rev. Sci. Instrum. 88, 033102 (2017).

${ }^{30}$ R. W. Joyner, M. W. Roberts, and K. Yates, Surf. Sci. 87, 501 (1979).

${ }^{31}$ F. Tao, Chem. Commun. 48, 3812 (2012).

${ }^{32}$ J. J. Velasco-Vélez, V. Pfeifer, M. Hävecker, R. Wang, A. Centeno, A. Zurutuza, G. Algara-Siller, E. Stotz, K. Skorupska, D. Teschner, P. Kube, P. BraeuningerWeimer, S. Hofmann, R. Schlögl, and A. Knop-Gericke, Rev. Sci. Instrum. 87, 053121 (2016).

${ }^{33}$ A. Knop-Gericke, V. Pfeifer, J.-J. Velasco-Velez, T. Jones, R. Arrigo, M. Hävecker, and R. Schlögl, J. Electron Spectrosc. Relat. Phenom. 221, 10 (2017).

${ }^{34}$ R. S. Weatherup, B. Eren, Y. Hao, H. Bluhm, and M. B. Salmeron, J. Phys. Chem. Lett. 7, 1622 (2016).

${ }^{35}$ J. Kraus, R. Reichelt, S. Günther, L. Gregoratti, M. Amati, M. Kiskinova, A. Yulaev, I. Vlassiouk, and A. Kolmakov, Nanoscale 6, 14394 (2014).

${ }^{36}$ K. Roy, L. Artiglia, and J. A. van Bokhoven, ChemCatChem 10, 666 (2018). 
${ }^{37}$ T. Masuda, H. Yoshikawa, H. Noguchi, T. Kawasaki, M. Kobata, K. Kobayashi, and K. Uosaki, Appl. Phys. Lett. 103, 111605 (2013).

${ }^{38}$ R. Delmelle, B. Probst, R. Alberto, A. Züttel, D. Bleiner, and A. Borgschulte, Rev. Sci. Instrum. 86, 053104 (2015).

${ }^{39}$ B. Bozzini, D. Kuscer, M. Amati, L. Gregoratti, P. Zeller, T. Dobrovolska, and I. Krastev, Surfaces 2, 295 (2019).

${ }^{40}$ C. Schlueter, A. Gloskovskii, K. Ederer, S. Piec, M. Sing, R. Claessen, C. Wiemann, C. M. Schneider, K. Medjanik, G. Schönhense, P. Amann, A. Nilsson, and W. Drube, Synchrotron Radiat. News 31, 29 (2018).

${ }^{41}$ C. Schlueter, A. Gloskovskii, K. Ederer, I. Schostak, S. Piec, I. Sarkar, Y. Matveyev, P. Lömker, M. Sing, R. Claessen, C. Wiemann, C. M. Schneider, K. Medjanik, G. Schönhense, P. Amann, A. Nilsson, and W. Drube, AIP Conf. Proc. 2054, 040010 (2019).

${ }^{42}$ S. K. Eriksson, M. Hahlin, J. M. Kahk, I. J. Villar-Garcia, M. J. Webb, H. Grennberg, R. Yakimova, H. Rensmo, K. Edström, A. Hagfeldt, H. Siegbahn, M. O. M. Edwards, P. G. Karlsson, K. Backlund, J. Åhlund, and D. J. Payne, Rev. Sci. Instrum. 85, 075119 (2014).

${ }^{43}$ T. Gronych, M. Jeřáb, L. Peksa, J. Wild, F. Staněk, and M. Vičar, Vacuum 86, 1759 (2012).
${ }^{44} \mathrm{M}$. Johansson, O. Lytken, and I. Chorkendorff, Topics in Catalysis 46(1-2), 175-187 (2007).

${ }^{45}$ W. Drube, Nucl. Instrum. Methods Phys. Res., Sect. A 547, 87 (2005).

${ }^{46}$ C. S. Fadley, J. Electron Spectros. Relat. Phenomena 178-179, 2 (2010).

${ }^{47}$ J. Zegenhagen, B. Detlefs, T.-L. Lee, S. Thiess, H. Isern, L. Petit, L. André, J. Roy, Y. Mi, and I. Joumard, J. Electron Spectros. Relat. Phenomena 178-179, 258 (2010).

${ }^{48}$ O. Karslıŏlu, S. Nemšák, I. Zegkinoglou, A. Shavorskiy, M. Hartl, F. Salmassi, E. M. Gullikson, M. L. Ng, C. Rameshan, B. Rude, D. Bianculli, A. A. Cordones, S. Axnanda, E. J. Crumlin, P. N. Ross, C. M. Schneider, Z. Hussain, Z. Liu, C. S. Fadley, and H. Bluhm, Faraday Discuss. 180, 35 (2015).

${ }^{49}$ M. S. Hegde, V. Jayaram, P. V. Kamath, and C. N. R. Rao, Pramana 24, 293 (1985).

${ }^{50}$ F. Mangolini, J. Åhlund, G. E. Wabiszewski, V. P. Adiga, P. Egberts, F. Streller, K. Backlund, P. G. Karlsson, B. Wannberg, and R. W. Carpick, Rev. Sci. Instrum. 83, 093112 (2012).

${ }^{51}$ D. Teschner, A. Pestryakov, E. Kleimenov, M. Hävecker, H. Bluhm, H. Sauer, A. Knop-Gericke, and R. Schlögl, J. Catal. 230, 186 (2005). 